\title{
Correction to: Surjectivity of Hadamard type operators on spaces of smooth functions
}

\section{Paweł Domański ${ }^{1} \cdot$ Michael Langenbruch $^{2}$ D}

Published online: 26 July 2018

(c) Springer-Verlag Italia S.r.I., part of Springer Nature 2018

\section{Correction to: RACSAM} https://doi.org/10.1007/s13398-018-0560-6

The presentation of Equation was incorrect in the proof section of the Theorem 2.18. The equation should be $\mathcal{E}^{\mathbf{2}(\mathbf{k}+\ell)+\sigma}$ instead of $\mathcal{E}^{\mathbf{2 ( \mathbf { k } + \ell + \mathbf { j } ) + \sigma}}$. The original article has been corrected.

The original article can be found online at https://doi.org/10.1007/s13398-018-0560-6.

$凶$ Michael Langenbruch michael.langenbruch@uni-oldenburg.de

1 Faculty of Mathematics and Comp. Sci., A. Mickiewicz University Poznań, Umultowska 87, 61-614 Poznań, Poland

2 Department of Mathematics, University of Oldenburg, 26111 Oldenburg, Germany 